\title{
Dyslexia and word reading problems
}

\author{
Rauno Parrila \& Athanassios Protopapas
}

\section{Introduction}

Developmental dyslexia is the most common learning disability in children, with prevalence estimates varying between $3 \%$ and $20 \%$ of all school age children (see e.g., Shaywitz, 1996; Snowling, 2013). It is acknowledged to affect children across languages, writing systems, and educational approaches to reading instruction. Developmental dyslexia is also the most widely studied behaviourally defined developmental disorder, with a rapidly expanding evidence base on associated genetics, neural functioning, cognitive skills, and environmental influences. In this chapter, we provide an overview of widely available cognitive theories of developmental dyslexia. Our review is by no means exhaustive in terms of theories included or the evidence for and against each of them-not even a book-length treatment (see, e.g., Elliot \& Grigorenko, 2014) could achieve that. We hope, however, that we cover the main theories and references driving the cognitive research on dyslexia at the moment.

Further, we limit our discussion of developmental dyslexia to alphabetic orthographies, and mainly to European alphabetic orthographies that have been studied most extensively. We make no claims about the universality of ideas presented (see McBride-Chang, this volume; McCardle, Miller, Lee, \& Tzeng, 2011; Nag, this volume; Share, 2008, for cross-linguistic issues in dyslexia and reading research) but acknowledge that as the theoretical models of developmental dyslexia develop and move from single-deficit models to multiple-deficit and hybrid models, their potential for accommodating specific features of different writing systems likely improves. 
Below, we will first define developmental dyslexia and then review what we call the single-cause theories of dyslexia that have traditionally dominated the field. We then advance to more recent double- and multiple-deficit deficit models, and conclude with a discussion considering the place of development and of the individual with dyslexia in developmental dyslexia research.

\section{Developmental Dyslexia Defined}

We define developmental dyslexia as a persistent and unexpected difficulty in developing age- and experience-appropriate word reading skills. For us, word reading skills include both accuracy and efficiency, defined as correctly read words per unit of time. Difficulty includes both performance that falls at the low end of the distribution for any given age and educational level as well as performance that may not be clinically low but can be maintained only with extraordinary effort. We take it for granted that word reading abilities are continuously distributed in a population and our definition potentially identifies as dyslexics those individuals who consistently fall at the lower end of the distribution on some word reading test(s). The cut-off between dyslexics and non-dyslexics is arbitrary and signifies no qualitative differences between those on different sides of the border.

By focusing on word reading problems, we distinguish between dyslexia and reading disability and argue that dyslexia is a subset of the latter. According to ICD-10, for example, specific reading disability requires impairment in reading comprehension, word recognition, oral reading, or in tasks that require reading. While dyslexia frequently leads to oral reading and reading comprehension problems, we suggest that dyslexia is present when the primary reading problem 
is at the level of words and the additional problems are either comorbid or secondary to the word reading difficulty.

By persistent we mean that the difficulty has to be present over some period of time and not easily remedied by an alternative instructional method. For example, if some children fail to learn to read words in grade 1 with one instructional method but then make clear progress with a different instructional method, they would not qualify as dyslexics (see e.g., Vellutino et al., 1996). Instead, we would call them "teaching disabled" (following Tunmer \& Greaney, 2010). Note, however, that persistence does not necessarily require early onset (see e.g., Catts, Compton, Tomblin \& Bridges, 2012; Torppa, Eklund, van Bergen \& Lyytinen, 2015).

Finally, our definition includes the element of unexpectedness. Despite potential problems in operationalization, this is necessary for distinguishing dyslexia from word reading difficulties in general. Unexpectedness requires that we can establish reasonable expectations not simply based on age. One such basis could be oral language comprehension (cf. Tunmer \& Greaney, 2010) but this is not typically included in definitions of dyslexia and may be problematic in that language skills and word reading are intertwined (e.g., Nation \& Snowling, 1998; Ricketts, Nation \& Bishop, 2007). Instead, many widely adopted definitions of dyslexia, such as those in DSM-5 and in ICD-10, that include the idea of unexpectedness state that poor general cognitive ability, sensory perception problems, or inadequate educational opportunities must be ruled out as possible causes of poor reading before a diagnosis of specific learning or reading disorder can be ascertained (see also International Dyslexia Association, 2002). 
Contrary to many definitions of dyslexia, we have no inclusion criteria. The most common inclusion criterion is an associated phonological processing deficit. We acknowledge that most individuals with dyslexia will exhibit a phonological processing deficit. However, a phonological deficit does not seem to be a necessary condition for dyslexia and many individuals with considerable word reading problems do not exhibit depressed phonological awareness scores (e.g., Georgiou, Parrila, Cui, \& Papadopoulos, 2013; Pennington et al., 2012; Torppa et al., 2013; van Bergen, Bishop, van Zuijen \& de Jong, 2015). Thus, it seems problematic to confine the use of the term - and the access to additional resources and accommodations that may come with it - to only those with phonological processing deficits, no matter how large a proportion they form of the total developmental dyslexia population.

\section{Single-Cause Theories of Developmental Dyslexia}

A traditional and most common theoretical approach to developmental dyslexia has been to posit a specific deficit in some cognitive or perceptual process to account for word reading difficulties. The deficit is typically observed on a signature nonreading task (or a narrow set of tasks) that is meant to expose some crucial underlying weakness. In most cases, the posited deficit is meant to account for impairments in learning to read rather than for dysfunction in the cognitive mechanism of mature reading; therefore, such proposals are best viewed as developmental, rather than neuropsychological, accounts of reading difficulties. In the terminology of Castles and Coltheart (2004), these theories concern distal causes rather than proximal causes, necessitating additional theoretical steps (and empirical demonstrations) to link them with observed reading performance. The following discussion considers some important 
aspects of a subset of influential approaches. Further information can be found in recent reviews by Ramus and Ahissar (2012) and Elliot and Grigorenko (2014).

\subsection{Phonological Deficits}

The currently dominating theory of developmental dyslexia posits a "phonological deficit" at the core of the problem for all or a large majority of children with difficulties learning to read words (Bishop \& Snowling, 2004; Ramus et al., 2003; Vellutino, Fletcher, Snowling, \& Scanlon, 2004). The phonological family of approaches to reading difficulties is empirically based on a set of tasks known as phonological awareness tasks in which children are asked to segment, blend, delete, or otherwise manipulate phonemes in oral tasks not directly associated with reading. A specific causal link between deficits in phonological awareness and word reading difficulties has been difficult to demonstrate conclusively due to interactions between reading and phonological awareness skills, such as the implication of orthographic processing in phonological awareness tasks (Castles \& Coltheart, 2004). However, this should not detract from the fact that poor performance in phonological awareness tasks is concurrently and longitudinally associated with dyslexia across languages (Ziegler \& Goswami, 2005).

In most phonological deficit theories, phonological awareness is assumed to be causally related to word reading because being able to deliberately individuate and identify phonemes in a spoken word is a prerequisite to consciously linking graphemes to those phonemes. However, additional theoretical steps are required to explain why reading difficulties persist past the initial stages or why phonological awareness predicts advanced orthographic 
knowledge as measured by word recognition and spelling tests. Moreover, difficulty in phoneme individuation and identification, impeding graphophonemic decoding, would be expected to cause major difficulties in reading unfamiliar letter strings, such as novel words and pseudowords. Indeed, poor pseudoword decoding has long been considered a hallmark of dyslexia. It is, however, increasingly acknowledged that word recognition is the most severely affected domain, with larger effect sizes between typical and poor readers than pseudoword decoding (Van den Broeck \& Geudens, 2012).

Alternative approaches to a causal link between phonological awareness tasks and reading development focus on phonological representations, assuming that the representations of phonemes are impaired, somehow improperly or insufficiently specified (Perfetti, 1992; Ramus, 2003; Snowling, 2000). Poor phonemic representations account for poor phonological awareness and graphophonemic decoding because phonemic representations are needed both for conscious manipulation and for efficient mapping to graphemes.

However, de-emphasizing the role of awareness overlooks the fact that tasks in which poor readers exhibit poor performance are consistently those in which phonological representations must be explicitly manipulated. There is little evidence that speech perception or production are affected, as would be expected if phonemic representations were impaired (Ramus \& Ahissar, 2012). Perception studies have reported inconsistent findings, including somewhat poorer (e.g., Rosen \& Manganari, 2001), no different (e.g., Hazan, MessaoudGalusi, Rosen, Nouwens, \& Shakespeare, 2009), or enhanced (e.g., Serniclaes, Van Heghe, Mousty, Carré, \& Sprenger-Charolles, 2004) discrimination of speech sounds. The online uptake of acoustic information in matching lexical candidates 
also appears normal (Magnuson et al., 2011). Given these challenges to the representation account, a deficit in phonological access, rather than representation, has been proposed (Boets et al., 2013; Ramus \& Szenkovits, 2008, 2009). According to this account, phonemes are properly specified but they are not efficiently accessible for operations such as those required for explicit phonological awareness tasks and for mapping between visual and phonological codes. It remains to be seen how this idea might account for the observed deficits once molded into specific theoretical hypotheses with associated empirical implications.

The dominance of the "phonological deficit" in theorizing about reading difficulties remains undisputed and most individuals with developmental dyslexia perform poorly in the signature tasks; at the same time, many children with phonological deficits develop into adequate readers. Other single-cause approaches tend to acknowledge these facts and fall into two categories: In the first, complementary or alternative domains of impairment are posited to explain word reading problems of different types. In the second category, the phonological deficit itself is attributed to a more general or lower-level dysfunction.

\subsection{Rapid Naming Deficit}

A second major branch of theorizing is based on "rapid automatized naming" (RAN) tasks (Denckla \& Rudel, 1976; Norton \& Wolf, 2012; Wolf \& Bowers, 1999; Wolf, Bowers \& Biddle, 2000). In these tasks, participants are shown an array of symbols (letters, digits, color patches, or objects) and asked to name them aloud sequentially as fast as possible. RAN tasks have been described as "an early, simpler approximation of the reading process," including "rapid, 
serial processing and integration of attentional, perceptual, conceptual, lexical, and motoric subprocesses" (Wolf et al., 2000, p. 393). The time to go through the entire array differentiates poor readers from good readers and is moderately to strongly correlated with word reading fluency, both concurrently and longitudinally, across languages and over a large age range (see review in Kirby, Georgiou, Martinussen, \& Parrila, 2010). Low performance in RAN tasks is termed a "naming deficit" and is considered causal to reading performance as an additional critical factor not subsumed under phonological processing.

RAN tasks are commonly thought to expose "rate problems" because of their multiple "processing speed requirements" (Wolf \& Bowers, 1999), thereby constituting a preferred predictor for reading fluency. Stated this way, it sounds like a method variance issue, with a timed predictor accounting for time-limited measures, but RAN also predicts reading accuracy (Kirby et al., 2010; Parrila, Kirby \& McQuarrie, 2004). Despite pronouncements regarding task complexity, in practice the theoretical emphasis has been placed on a general "processing speed" construct that affects cognitive components required for symbol processing. However, naming single symbols displayed individually is not a strong predictor of reading performance or reading difficulty (Jones, Branigan, \& Kelly, 2009; Zoccolotti et al., 2013; Zoccolotti, De Luca \& Spinelli, 2015). The array presentation format, with multiple stimuli displayed simultaneously, is critical to the predictive power of the task (Georgiou et al., 2013). Therefore processes involved in naming individual symbols cannot account for the RANreading relationship, regardless of their speed requirements. Instead, it must be the efficiency in sequentially naming an array of symbols that brings out 
variance uniquely related to reading (Gordon \& Hoedemaker, in press; Protopapas, Altani, \& Georgiou, 2013).

At the moment, the "naming deficit" theory concerns primarily an assessment issue rather than a coherent explanatory approach to reading development. Performance on RAN tasks helps identify children with reading difficulty that cannot be attributed to phonological deficits. Moreover, children with low RAN performance in addition to poor phonological awareness tend to be the poorest readers (Kirby, Parrila \& Pfeiffer, 2003; Torppa et al., 2013) who likely benefit least from traditional intervention (Kirby et al., 2010).

The well-documented relationships between RAN and reading remain largely unexplained (see Georgiou \& Parrila, 2012, for a review). Although current research efforts focus on the crucial aspect of the task format (de Jong, 2011; van den Boer, Georgiou, \& de Jong, 2016), it is not theoretically necessary that the difficulties arise directly from the cognitive components responsible for processing sequences (Zoccolotti et al., 2015). Perhaps a relatively minor difficulty in naming individual symbols becomes exacerbated due to the relentless requirements for rapid integration among cognitive processes when going through a sequence of symbols. Access to phonological representations or visual symbol identification cannot provide the explanation because articulation of the symbol names is necessary for the crucial individual differences to emerge (Georgiou et al., 2013). Yet, articulation rates are not the answer either because silent intervals between symbols ("pause times") within the RAN task are also correlated with reading (Georgiou, Aro, Liao, \& Parrila, 2015). While RAN performance has been actively studied for years across multiple laboratories and languages, at present the "naming deficit" approach remains a placeholder for 
the future identification of putative cognitive and neural processes underlying efficient word and text reading.

\subsection{Auditory processing}

The lack of direct evidence for impaired phonological representations notwithstanding, a number of research programs have sought to account for the deficient phonological representations by addressing either general auditory processing or speech-specific processing underlying phonetic perception. Each of these approaches has been based on a signature measure, or a narrow set of measures, in which significant differences are often found between groups with developmental dyslexia and groups of typically developing readers. For example, “rapid auditory processing” (Gaab, Gabrieli, Deutsch, Tallal \& Temple, 2007; Tallal, 1980) is assessed with a "repetition test," in which two brief stimuli are presented in rapid succession and the participant must report them in the correct sequence; "temporal sampling" (Goswami, 2011, 2015) is assessed with a "risetime perception test," in which stimuli differing in onset abruptness must be distinguished; an "allophonic mode of speech perception" (Noordenbos, Segers, Serniclaes, \& Verhoeven, 2013; Serniclaes et al., 2004) is assessed with categorical perception tasks including identification and discrimination of synthetic speech syllables; and so on.

At the moment, robustness and interpretation of the initial results remains controversial (see Protopapas, 2014, and Ramus \& Ahissar, 2012, for discussion and references). First, the purported deficits do not reliably emerge in every study; failures to replicate and partial replications abound. Second, despite the significant group differences, when individual performance is examined it is invariably found that a majority of participants in the reading impaired group 
perform within the range of performance of the typically developing group. This is unlike phonological awareness, low performance in which is typically observed for the majority of reading impaired individuals. Moreover, besides group differences in the target tasks, differences are systematically observed in tasks that, according to the theory being tested, should not be affected. Because the tasks pose complex cognitive requirements for successful performance, it remains plausible that performance differences may be attributable to perceptual or cognitive aspects of carrying out the task other than the hypothesized auditory processing requirements.

Moreover, for a causal interpretation of differences in auditory processing, the hypothesized deficits must demonstrably precede and predict mediating deficits, which in turn must precede and predict reading difficulties. Precedence can only be established in longitudinal studies beginning at pre-reading ages (Boets et al., 2011), a goal not easy to achieve in practice. The existing comparisons to age-matched control groups confound performance with all kinds of experience and expertise associated with reading. Far from solving this problem, the alternative reading-level match designs confound group with age and can only reveal developmental and distributional aspects of the measures rather than theoretically important differences among individual children (Van den Broeck \& Geudens, 2012). As it is becoming clear that phonological representations may not be impaired in the sense originally thought, it remains to be determined whether and how low performance in various psychophysical tasks may be involved in the formation of and access to phonological representations or otherwise in learning to read. 


\subsection{Visual attention}

An entirely different set of alternative approaches to explaining developmental dyslexia have focused on visual-spatial attention (Vidyasagar \& Pammer, 2010). One proposal is based on a "letter span" task, in which a set of five letters is flashed briefly on the screen and the participant is asked to report either all of the letters or a single letter in a position cued after their disappearance. It is hypothesized that this task assesses the number of visual elements that can be processed simultaneously, as required for efficient reading. A "visual attention span" deficit is posited as complementary to the phonological deficit approach or it can exist independently and account for reading problems in the absence of phonological deficits (Bosse, Tainturier, \& Valdois, 2007; Zoubrinetzky, Bielle, \& Valdois, 2014).

The use of letters as stimuli in the critical task admits alternative interpretations besides visual attention. For example, uptake of visual letter information may be limited due to insufficient reading experience, or inefficient graphophonemic connections may slow down activation of phonological codes for the letters through feedback loops. Diminished effects have been reported with stimuli other than letters or digits (Ziegler, Pech-Georgel, Dufau, \& Grainger, 2010), though subsequent visual categorization data (Lobier, Zoubrinetzky, \& Valdois, 2012) and neuroimaging data (Lobier, Peyrin, Pichat, Le Bas, \& Valdois, 2014) were unaffected by stimulus type. Still, the causal directionality of the visual attention span remains to be independently verified because reading practice may conceivably affect visual attentional efficiency and multi-element processing of non-alphanumeric stimuli as well (Dehaene et al., 2010). 
A more recent proposal is based on a spatial cueing task, in which the location of a symbol on the screen is briefly cued prior to its appearance. Italian children with dyslexia were found to benefit less from correct cueing than typically developing readers (Facoetti et al., 2006, 2010). In a prospective longitudinal study, the performance of preschoolers on this task was found to predict their reading performance in grades 1 and 2 . This has been interpreted as evidence for a fundamental deficit in orienting visual attention, termed "sluggish visual attention," theorized to underlie letter and word recognition (Franceschini, Gori, Ruffino, Pedrolli, \& Facoetti, 2012). However, this proposal is not specifically related to letter and word identification performance. Rather, the link to word recognition is through phonological decoding, via a multimodal attention mechanism that mediates efficient orthographic-phonological binding (Gori \& Facoetti, 2015).

\subsection{Discussion of single-deficit theories}

Most of the single-deficit theories of dyslexia offer little more than observation of an association between poor reading performance and low performance in a signature nonreading task (or in a narrow set of tasks). The most successful among them, the phonological deficit and the naming speed deficit theories, include evidence for longitudinal associations and findings that are more robust across studies. However, much more will be needed before a "theory of dyslexia" can be proclaimed. We highlight here two obstacles evident in current theorizing about dyslexia, namely, (a) understanding task performance and (b) constructing causal theories of reading development that involve the necessary theoretical constructs to connect reading with the signature tasks. 
Signature task performance is often taken to index a specific target construct, ignoring other cognitive and perceptual requirements for successful performance. For example, performance on phonological awareness tasks may be taken to index the quality of phonological representations even though successful task performance also requires accurate perception, retention in short-term and working memory, manipulation, and formation and execution of an articulatory response. Weaknesses in any of these steps or in their integration will impair task performance without necessarily involving poor quality of the phonological representations. Similarly, performance in rapid naming tasks, risetime perception tasks, letter report tasks, etc., will necessarily involve a multitude of perceptual and cognitive processes and representations, any of which might be implicated in poor performance. Importantly, the "weak link" need not be a single step or process: perhaps two or more elements might need to be compromised before performance decrements can be observed. This possibility cannot be addressed in the absence of in-depth task analyses.

The validity of a task indexing a construct cannot be determined a priori. Convergent and divergent validity must be demonstrated by reference to additional tasks that do or do not share the purported critical representation or process. For a theoretical proposal to stand on solid ground, the crucial theoretical constructs must be properly operationalized by their empirical indices. This must include a wide range of tasks hypothesized to involve the construct in question. Crucially, it must also exclude tasks of similar form and comparable difficulty that do not involve the construct. In the absence of welldefined constructs, theoretical connections are posited in a vacuum. 
Second, the theoretical constructs must be unambiguously implicated in a causal theory that clearly shows how they underlie poor reading performance. Admittedly, it is not clear how this can be achieved in the absence of a welldefined theory of reading development and reading performance. Still, it behooves the proponents of specific theories of dyslexia to explain how learning to read depends on the hypothesized theoretical constructs and to demonstrate the dependence in properly controlled longitudinal and experimental studies that simultaneously assess convergent and divergent construct validity and also include tasks assessing alternative hypotheses for the same individual differences. Intervention studies in particular can be effective if training in a distal domain can be shown to affect reading skill. However, it must be clearly demonstrated that the effect arises specifically due to the theoretically hypothesized aspect of training. This is only achievable in the context of not simply active control groups but of a well-matched control training regime that differs only in the theoretically critical feature from the proposed intervention.

\section{Acknowledging Heterogeneity: Subtypes of Dyslexia}

One principled approach to the heterogeneity of word reading difficulties has been through subtyping. That is, if a single-deficit theory cannot account for all cases of reading failure, perhaps a combination of theories will. There may be two (or more) kinds of problems potentially impeding word reading development, therefore two (or more) kinds of developmental dyslexia. As a consequence, children can still be "dyslexic" if their word reading is below par, but assigned to "type A," "type B," or a "combined A+B" dyslexic group depending on some relevant profiling. The categorization may be based on measures of reading performance or on other cognitive, linguistic, or perceptual indices, 
including the signature tasks discussed above. We review here the most prominent examples of such subtyping.

\subsection{Phonological vs. Surface Dyslexia}

Perhaps the best-established approach to subtyping is based on a theoretical distinction originally drawn in neuropsychological English-speaking patients (Coltheart, 2012). Specifically, it was observed that, following brain damage, certain patients have reading difficulties that manifest differentially with different types of letter strings: Some patients have more difficulty with unfamiliar or made-up words (pseudowords) whereas other patients have more difficulty with familiar but inconsistent words, that is, words that are pronounced differently from other words with similar spelling patterns (Woollams, 2014).

The distinction between consistent and inconsistent words is especially relevant for the English orthography, in which there is a great range of graphophonemic consistency, including words with pronunciation hardly licensed by their spelling, such as yacht and rough. An absolute division between "regular" and "irregular" words has been imposed on a continuum of consistency, based on the theoretical assumption of content-independent "rules" for graphophonemic conversion. Any word not fully pronounceable by the rules is termed "irregular" regardless of its relations to other words. For example, the word pint is deemed irregular for failing to adhere to the same pattern as mint and hint, even though the usual mappings hold for three out of its four letters and pronunciation of the letter $i$ in this context is consistent with the word pine (Plaut, McClelland, Seidenberg, \& Patterson, 1996). The developmental 
plausibility and cross-linguistic relevance of this rule-based distinction remain controversial.

The differential patterns of impairment seen in patients with acquired dyslexia, in conjunction with the theoretical hypothesis of absolute graphophonemic rules, have led to a two-pronged approach to word reading, including a "nonlexical" route assigned to applying rules and a "lexical" route to recognize familiar words (Coltheart, Rastle, Perry, Langdon, \& Ziegler, 2001). Accordingly, two alternative routes to failure can be posited: Damage to the nonlexical route impedes graphophonemic conversion whereas damage to the lexical route impedes recognition of familiar words. The effects of damage would be most obvious on pseudowords and irregular words, respectively, because these can only be read by the corresponding route. In contrast, regular words can be read correctly by either route, and therefore they are not diagnostic. Children with difficulties in pseudoword reading are termed "phonological" dyslexics whereas those with difficulties in irregular word reading are termed "surface" dyslexics, consistent with the classification of neuropsychological patients (Castles \& Coltheart, 1993).

Although theoretically attractive in its simplicity, this proposal has met with empirical difficulty in that the vast majority of children with reading difficulty exhibit low performance with all kinds of words and pseudowords (Manis, Seidenberg, Doi, McBride-Chang, \& Petersen, 1996), raising concerns about the parsimony of positing simultaneous impairment in both routes. The surface subtype has also been elusive in investigations using reading-level match designs (Manis et al., 1999; Stanovich, Siegel, \& Gottardo, 1997). As for the phonological subtype, it has long been known that the pseudoword reading 
deficit is contingent on item difficulty, emerging mainly with complex pseudowords that do not resemble words (Rack, Snowling, \& Olson, 1992). Recent advances in understanding the psychometric issues in comparing performance decrements across domains, such as between words and pseudowords (Van den Broeck \& Geudens, 2012), have further undermined the potential for defining subtypes on the basis of relative performance in such tasks.

\subsection{Double-Deficit Theories}

Proponents of visual and naming deficit theories reviewed above have taken a slightly different approach to subtyping. Low performance in the signature task (letter span or rapid naming) is attributed to an underlying deficit that impedes reading development independently of phonological deficits. Therefore, the visual or naming deficits are seen as alternative or additional to the phonological deficit, supporting classification into four quadrants: Children without difficulty, children with a phonological deficit, children with a visual/naming deficit, and children with a double deficit (Bosse et al., 2007; Wolf \& Bowers, 1999). This permits explanation of poor reading in the absence of phonological problems, which remains a thorny issue for proponents of the phonological core approach. The double deficit approaches also provide an additional dimension of severity, possibly associated with poorer response to intervention, insofar as children with a double deficit would suffer from more pervasive and severe difficulties, which may also be more difficult to ameliorate (Wolf et al., 2000).

How deficits are associated with reading performance varies across the double deficit approaches. In the original double deficit theory of Wolf and Bowers (1999), naming speed deficits impede the development of efficient word 
recognition, whereas phonological deficits affect the development of accurate decoding; combined deficits impede reading development on both fronts, resulting in more severe difficulties. Bosse et al. (2007), in turn, suggested that visual attention deficits impair visual word processing more generally, manifesting themselves in decoding as well, even in the absence of frank phonological deficits. Thus, the visual attention span is proposed to account for reading problems potentially including those typically attributed to impaired phonological processing. Nevertheless, visual attention span problems are expected to affect sight word reading more severely than phonological decoding. Finally, proponents of visual attention deficits based on spatial cueing tasks have claimed that deficits in spatial attention specifically affect processes related to phonological decoding (Ruffino, Gori, Boccardi, Molteni, \& Facoetti, 2014). In this approach, subtypes do not distinguish among patterns of reading performance but, rather, among patterns of cognitive skills that underlie similar difficulties in word reading.

\subsection{Discussion of Subtyping Theories}

The move from a single phonological-core approach towards encompassing alternative cognitive substrates of word reading difficulties seems welcome in the context of the established cognitive heterogeneity in the low end of the word reading performance spectrum. Freedom from the tyranny of a single cause may pave a path toward a more pervasive acceptance of a multitude of potential routes to word reading difficulties. However, theories defining subtypes on the basis of low performance in specific signature tasks are more strongly related to single-cause theories than to multiple deficit alternatives discussed below in that they seek to identify circumscribed, distinct causes for specific patterns of word 
reading difficulties. Thus, they also inherit problems associated with single-cause approaches, including those stemming from the heterogeneity of reading problems, which may not fit entirely within any particular classification. For example, the alternatives reviewed above would already lead one to expect a future triple- or quadruple-deficit theory of dyslexia.

Moreover, subtyping proposals raise additional concerns regarding the reliability and stability of the classification, in addition to the validity of the constructs underlying the classification. Reliability is difficult to assess conclusively due to the arbitrariness of cutoff points placed on continuous performance distributions. As task performance is inherently noisy, the reliability of classification depends on the reliability of the signature tasks. Here, issues of theoretical importance (e.g., intraindividual variability) may be dismissed as trivial measurement noise. Stability of subtyping has been found to be moderate for surface vs. phonological dyslexia (Manis et al., 1999) and for naming speed vs. phonological deficit (Steacy, Kirby, Parrila, \& Compton, 2014). Although studies addressing a specific distinction may not generalize to other subtyping approaches, it behooves the proponents of subtypes to demonstrate the reliability and stability of classification over large and representative populations across languages.

\section{Multiple-Deficit Models of Dyslexia}

The evidence reviewed above suggests that single-, double- or triple-cause theories of developmental dyslexia are unlikely to provide satisfactory explanations of dyslexia as a behaviorally defined developmental disorder. There is now widespread consensus that the term "dyslexia" refers to the low end of a word reading distribution rather than to a discrete condition. If there is no 
discrete condition that accounts for the great majority of children with word reading difficulties, the search for specific causes is greatly challenged. Rather, the focus is turning to multifactorial developmental pathways that can give rise to brains that differ in their propensity for learning to read (or learning math, or acquiring any other cultural artifact our evolution has not specifically equipped us for). Individual differences in language and reading development are increasingly attributed to a multitude of interacting genetic, neural, cognitive, behavioral, and environmental factors, potentially leading to high or low reading performance via multiple developmental pathways.

In some theoretical models, cognitive multiplicity is assumed to reduce to a single genetic or neural cause for developmental dyslexia, but these calls for simplicity face sizeable empirical challenges. The genetic studies of dyslexia started with the expectation of dominant inheritance controlled by a single gene (Hallgren, 1950). Specific susceptibility genes were sought with single-gene strategies (such as genetic linkage, targeted association, and chromosome translocation or deletion). Instead, multiple loci with multiple susceptibility genes have been identified (Kere, 2014). Molecular and behavior genetic studies of dyslexia now agree that the genetic architecture associated with dyslexia is complex, polygenic (two or more genes contribute to the phenotype), and heterogenic (the same behavioral outcome can be associated with multiple different causes; Carrion-Castillo, Franke, \& Fisher, 2013; Elliot \& Grigorenko, 2014). There are examples of families where the inheritance pattern is consistent with a rare mutation of a single gene (e.g., de Kovel et al., 2004; Nopola-Hemmi et al., 2000). However, all genes identified in rare familial forms of dyslexia jointly explain a tiny fraction of the variance in reading ability when 
tested with larger samples. Instead, most cases of dyslexia are probably affected by a very large number of genes, each with only weak effects (Carrion-Castillo et al., 2013), further complicated by a multitude of gene $\times$ gene and gene $\times$ environment interactions (Bishop, 2015; Jablonka \& Lamb, 2014).

Neural level examinations have not fared much better in simplifying dyslexia theories. Recent meta-analyses of functional neuroimaging studies (Maisog, Einbinder, Flowers, Turkeltaub, \& Eden, 2008; Richlan, Kronbichler, \& Wimmer, 2009, 2011) have identified more than a hundred foci of differences between dyslexic and normally developing readers. The results from the metaanalyses were mostly consistent with the typical neurophysiological account of developmental dyslexia for adults (e.g., Pugh et al., 2000) but highlighted the need for refinement in the developmental account. In particular, Richlan et al. (2011) found no brain areas typically associated with phonological coding to be reliably underactivated across studies. Their results did not support the assumption that the primary and early emerging dysfunction resides in the left temporo-parietal cortex housing the dorsal reading subsystem. Instead, they suggested that an early and limited left occipito-temporal dysfunction becomes extended over time and is accompanied by a left temporo-parietal dysfunction by adulthood.

As individual functional imaging studies continue to produce widely varying results, it may be necessary to examine how much of this variability is related to heterogeneity (beyond age) in the dyslexia samples and how much is related to variability in imaging and analysis methods and the signature tasks used in different laboratories. Notably, substantial variability is not limited to functional imaging but is also present in structural imaging, as demonstrated in 
meta-analyses of voxel-based morphometry studies of gray matter (Linkersdörfer, Lonnemann, Lindberg, Hasselhorn, \& Fiebach, 2012; Richlan, Kronbichler, \& Wimmer, 2013; see review in Jednorog et al., 2015) and white matter (Vandermosten, Boets, Wouters \& Ghesquière, 2012) comparing disabled and typically developing readers. As structure and function of the brain are both altered by experience (Gabrieli, 2009; Krafnick , Flowers, Luetje, Napoliello, \& Eden, 2014; Simos et al., 2002), the relevant heterogeneity in the developmental dyslexia samples is not limited to the reading and cognitive measures usually used to identify the dyslexics.

\subsection{Probabilistic Multiple Deficit Models}

The assumption that behaviorally defined developmental disorders can have a single cause at any level of analysis has been further challenged by multifactorial etiological models (e.g., Gottlieb \& Halpern, 2002; Lyytinen et al., 1998; Pennington, 2006; van Bergen, van der Leij, \& de Jong, 2014). In an influential paper, Pennington (2006) reviewed genetic, neural, cognitive, and comorbidity studies of developmental dyslexia and concluded that converging evidence precipitates a major reconceptualization of the existing theoretical models. He argued that probabilistic multiple deficit models (PMDM) are needed to provide realistic accounts of developmental disorders, their comorbidity, and the nondeterministic relationships between disorders and their presumed causes. He suggested further that such PMDMs must include protective and risk factors, multiple levels of analysis, bidirectional connections between constructs within each level (horizontal or intralevel interactions), and bidirectional connections between levels (vertical or interlevel interactions) to account for interactions between protective and risk factors functioning at different levels of 
analysis (see also, Ford \& Lerner, 1992; Gottlieb, 1983, 1997; Gottlieb, Wahlsten, \& Lickliter, 2006; Lyytinen et al., 1998).

Figure 1 shows a simplified version of Pennington's (2006) PMDM with interlevel connections omitted. The left side of the model shows the levels of analysis - etiological, neural, cognitive, and behavioral - and the right side displays the mechanisms that underlie horizontal interactions in each level. According to Pennington, the etiological level of any behaviorally defined developmental disorder - including dyslexia - is multifactorial and involves interaction of multiple risk and protective factors that can be either genetic or environmental; these jointly and probabilistically influence the development of neural systems and, further, the cognitive processes they support. At the behavioral level, the disorder is jointly and probabilistically produced by multiple cognitive risk and protective factors, each influenced by multiple etiological factors. Some of the etiological risk and protective factors influence several disorders (causing comorbidity) whereas others are specific to one disorder. No single etiological, neural, or cognitive factor is sufficient; a combination of several may be necessary to produce the behavioral symptoms that define the disorder. Finally, the liability distribution for any given disorder is continuous. An individual's position on the distribution is affected by risk and protective factors at any level.

Recently, van Bergen et al. (2014) extended Pennington's PMDM to allow for intergenerational transfer of risk and protective factors. To explicitly account for parental effects, they proposed the intergenerational multiple deficit model (iMDM; see Figure 2), which includes not only genetic transmission from parents to children but also passive and evocative gene-environment correlations and 
cultural transmission from parents. In Figure 2, environment as shaped and selected by the parents is separate from extra-parental environment and from genetic effects in the etiological level of Pennington's formulation. In the iMDM, parental skills (as expressed in their phenotype, PT) are transmitted both genetically and via the home environment. This extended home environment can exert a direct effect (cultural transmission in Figure 2) on children in that parents' cognitive phenotypes impact the environments they can offer for their children, including the protective and risk factors in these environments. If home environment correlates with parents' and child's genotype, we observe passive gene-environment correlation (rGE in Figure 2); these influences could, for example, include highly literate parents having a higher income and thus access to better schools. Evocative rGE arises when some of the child's highly heritable characteristics (e.g., good phonological awareness) elicit a response from the environment (e.g., more rhyming and alliteration games and playing with letters) that further strengthens the child's reading development. Shared environmental confound contributes to parent-child resemblance by affecting reading ability in both generations. For example, access to education, particularly for females, is a significant shared environmental confound in many parts of the world. Another such confound could be a shared home language that is different from the language of education.

Separating environment from genes as etiological factors allowed van Bergen et al. to also differentiate between environment as shaped by parents and extra-parental environment that parents have less influence over; this could include reading instruction method, access to print and digital media, peer influences, legislation of special provisions and resources in the schools for 
students with dyslexia, and the value of literacy in the society at large. Van Bergen et al. also distinguish between active rGE (e.g., a child who learns to read easily is motivated to read more and seeks out opportunities to do so in the environment) and evocative rGE, where children's genetically influenced ability elicits differential reactions from the environment, such as good readers being given more demanding materials to read. In the educational literature, a similar difference is made between the active and evocative impact a child can have on teachers' behavior (e.g., Nurmi, 2012).

\subsection{Discussion of Multiple Deficit Models}

Multiple deficit models provide an interesting meta-theoretical framework to advance developmental dyslexia theorizing and research. These models are examples of dynamic or developmental systems models that have a long history in developmental embryology and biology (see e.g., Gottlieb, 2002) and have permeated developmental sciences for some time (see e.g., Ford \& Lerner, 1992, and Thelen \& Smith, 1994, for introductions to earlier approaches, and Molenaar, Lerner \& Newell, 2014, for newer formulations). While several prominent authors have recently acknowledged the limitations of traditional models (e.g., Catts, this volume; Snowling \& Melby-Lervåg, 2016), systems approaches in general have had little traction in dyslexia research (however, see Morrison \& O'Connor, this volume, for an example of a systems approach to reading development), perhaps because systems approaches pose formidable empirical challenges and theoretical questions the answers to which poorly match our dominant research traditions and presuppositions..

While there are multiple families of developmental or dynamic systems theories, the PMDM models as outlined by Pennington (2006) and van Bergen et 
al. (2014) bear a close theoretical resemblance to developmental psychobiological systems theories (e.g., Gottlieb et al., 2006). In these theories, development is conceptualized as a sequential emergence of new structural and functional properties and competencies at all levels of analysis as a consequence of horizontal and vertical interactions among the parts (Gottlieb et al., 2006). This implies that any causal explanation of a developmental outcome, such as dyslexia, must describe the developmental system that, over time, led to the observed outcome. While we can study components of the system, such as rapid naming tasks or individual genes, in relative isolation, individual components neither explain nor cause (normal or abnormal) development in any meaningful sense without an account of the rest of the system; such an account must include the organism and the physical, biological, and social factors ("developmental niche") that interact with and shape it over time. As the components, or interactants, in these developmental networks are themselves largely products of earlier development, developmental explanations require that we study their interactions over a period of time. As a result, we need to rethink both what constitutes an explanation and what kinds of observations are required to understand the developmental pathways to the observed outcomes.

As developmental systems models, PMDMs inherit the idea that an explanation requires understanding the developmental system with all of its risk and protective factors. Thus, the unit of explanation is not an individual but a relational causal network. Relational causal networks include the idea that no single element or level in the developing system has causal primacy, and the functional significance of any element on development can only be understood in the context of the developmental system of which they are part. At each level of 
the developmental system, the effect of any element is dependent on the rest of the system, making all factors potentially interdependent and mutually constraining (Gottlieb, 1991).

The PMDMs reviewed above imply this kind of multidimensionality where assigning causal priority to any level is problematic. However, these ideas seem difficult to reconcile with current theorizing that assigns causal priority at the genetic level and assumes that genetic and environmental influences are additive. In contrast, the developmental systems view leads to conceptualizing genetic and environmental effects as interdependent. At least in principle, genetic (and other inherited) effects leading to individual differences cannot be understood apart from development occurring in a specific environmental context. Complex human behaviors, such as reading, "are influenced by hundreds or thousands of proteins encoded in hundreds or thousands of genes of small effect that interact with one another, the environment, and the epigenome in complex ways" (Charney \& English, 2012, p. 30). What then constitutes an explanation of development and developmental outcome is much more complex than most developmental models in developmental dyslexia research currently acknowledge.

Methodologically, we need to supplement current nomothetic variablecentered studies with idiographic studies and person-centered analyses (see examples in Molenaar et al., 2014). Nomothetic variable-centered studies that have driven most of the theory development described above are informative of general tendencies and the components that explanatory models need to include, but they cannot predict how the process of development unfolds over time. We suggest that we need to develop and test "dynamic mechanistic explanations" 
(Bechtel \& Abrahamsen, 2005, 2010) of how different interactants work together in producing observable outcomes. While we currently have few such models to build on (see Giraud \& Ramus, 2013, for an exception), these kinds of models are not uncommon in other fields of inquiry (see, e.g., Becher et al., 2014, for a complex model of honeybee colony dynamics). Dynamic mechanistic explanations require longitudinal and experimental studies, going beyond individual differences to observations of developmental mechanisms, as well as computational modeling (e.g., agent-based models, see Railsback \& Grimm, 2011) of these mechanisms grounded in empirical observations and aiming to understand their functioning where observations and experimentation are not possible. For example, if we conceptualize genetic, neural, and cognitive interactants suggested by Giraud and Ramus (2013) as agents and model their functioning and interactions with agent-based models (see e.g., Railsback \& Grimm, 2011; Wilensky \& Rand, 2015; examples at https://ccl.northwestern.edu/netlogo/) that first simulate what we already know, we can then start to posit mechanisms and conditions under which they operate. As we learn more, the models will get more complex by having to include simulations of new empirical findings and they will produce new hypotheses to examine empirically (see Bechtel \& Abrahamsen, 2010, for an example of increasing model complexity). The scope of the studies does not have to be any more expansive than the studies we already conduct, but when we use models as first approximations of the developmental interactions between the components we observe, the explicitness of our theories will increase because we will have to focus on the mechanisms and not only on associations among measures. 
Finally, the notion of equifinality has become an axiom of developmental systems theory (see e.g., Ford \& Lerner, 1992; Gottlieb et al., 2006). In this view, organisms with different early_or "initial" — conditions can reach the same endpoint and organisms with the same initial conditions can take different routes or pathways to reach a common endpoint. Equifinality is an important principle in psychological development, but the concept is seldom discussed in developmental dyslexia research. However, if PMDM models are interpreted as developmental systems theories, it follows that development is influenced by many risk and protective factors that interact to produce the reading behavior we use to diagnose dyslexia. Such complex probabilistic networks are bound to produce similar observable states with different interactants (e.g., different explanations of word reading failure; Snowling \& Melby-Lervåg, 2016). Examples are bound to proliferate with increased emphasis on person-centered and idiographic methods.

\section{Conclusion}

Theories of developmental dyslexia cannot simply be theories of individual differences in word reading development; instead, they need to progress towards dynamic mechanistic explanations of various developmental pathways to inaccurate or inefficient word reading. The former are general and meant to account primarily for associations among general constructs, effectively describing the average situation that may not apply to any individual (see e.g., Velicer, Babbin, \& Palumbo, 2014). However, if the goal is to develop a theory of dyslexia as a specific condition rather than a diagnostic label, then we need a much more specific theory, of a more applied nature. This theory should account for each and every child that deservedly receives the diagnostic label "dyslexia" 
following extensive testing, examination, and possibly failed intervention. There is no room for letting some children slip. However large and heterogeneous, groups of children with dyslexia must be fully accounted for by any theory purporting to be a theory of dyslexia. Otherwise it is not really a theory of dyslexia but maybe a theory of some of the difficulties of some of the children who fail to learn to read words. The requirement for full diagnostic coverage seems extremely unlikely to be satisfied by any approach focusing on single causes or single-factor characterizations, and it seems very likely to include multiple pathways to the same behavioral condition.

The above discussion has indicated a number of potential interactants from the genetic through the environmental level that need to be considered in a developmental systems theory of developmental dyslexia. These interactants were identified in variable-centered studies focusing on individual differences because (a) we know to measure them, and (b) they co-vary sufficiently with the dependent variable in the examined samples. We suspect that the interactants we currently know of as "actual difference makers" (Waters, 2007) are but a small subset of those needed for a dynamic mechanistic theory of developmental dyslexia. We may have already included some "potential difference makers" (Waters, 2007; see also Griffiths \& Tabery, 2013, and Tabery, 2014) in our empirical studies but failed to recognize their significance for a developmental theory of dyslexia because they either did not vary sufficiently to produce the statistical association, or the heterogeneity of their expression in the samples drowned the signal. However, there are undoubtedly more potential difference makers at all levels of analysis that are yet to be identified. Here is where singlecase studies and exploratory computer modeling can capture extreme cases to 
enhance theory development. The truly developmental science of developmental dyslexia requires that we "deconstruct" the phenomenon at each level into its constituents, but also that we then attempt to reconstruct the developing system to test hypotheses about interactions between levels and mechanisms of effect. The theories we want are the ones that not only explain why a child with dyslexia reads differently from another child with or without dyslexia, but also where in that developmental system we can intervene successfully. 


\section{References}

Becher, M. A., Grimm, V., Thorbek, P., Horn, J., Kennedy, P. J. \& Osborne, J. L. (2014). BEEHAVE: A systems model of honeybee colony dynamics and foraging to explore multifactorial causes of colony failure. Journal of Applied Ecology, 51, 470-482.

Bechtel, W. \& Abrahamsen, A. (2005). Explanation: A mechanistic alternative. Studies in History and Philosophy of Biological and Biomedical Sciences, 36, $421-441$

Bechtel, W. \& Abrahamsen, A. (2010). Dynamic mechanistic explanation: computational modeling of circadian rhythms as an exemplar for cognitive science. Studies in History and Philosophy of Science, 41, 321-333.

Bishop, D. V. M. (2015). The interface between genetics and psychology: Lessons from developmental dyslexia. Proceedings of the Royal Society B, 282: 20143139.

Bishop, D. V. M., \& Snowling, M. J. (2004). Developmental dyslexia and specific language impairment: Same or different? Psychological Bulletin, 130, 858886.

Boets, B., de Beeck, H. P. O., Vandermosten, M., Scott, S. K., Gillebert, C. R., Mantini, D., ... \& Ghesquière, P. (2013). Intact but less accessible phonetic representations in adults with dyslexia. Science, 342, 1251-1254.

Boets, B., Vandermosten, M., Poelmans, H., Luts, H., Wouters, J., \& Ghesquière, P. (2011). Preschool impairments in auditory processing and speech perception uniquely predict future reading problems. Research in Developmental Disabilities, 32, 560-570. 
Bosse, M. L., Tainturier, M. J., \& Valdois, S. (2007). Developmental dyslexia: The visual attention span deficit hypothesis. Cognition, 104, 198-230.

Carrion-Castillo, A., Franke, B. \& Fisher, S. E. (2013). Molecular genetics of dyslexia: An overview. Dyslexia, 19, 214-240.

Castles, A., \& Coltheart, M. (1993). Varieties of developmental dyslexia. Cognition, 47, 149-180.

Castles, A., \& Coltheart, M. (2004). Is there a causal link from phonological awareness to success in learning to read? Cognition, 91, 77-111.

Catts, H. W., Compton, D., Tomblin, J. B., \& Bridges, M. S. (2012). Prevalence and nature of late-emerging poor readers. Journal of Educational Psychology, $105,166-181$.

Charney, E. \& English, W. (2012). Candidate genes and political behavior. American Political Science Review, 106 (1), 1-34.

Coltheart, M. (2012). Dual-route theories of reading aloud. In J. S. Adelman (Ed.), Visual word recognition, volume 1: Models and methods, orthography and phonology (pp. 3-27). Hove, UK: Psychology Press.

Coltheart, M., Rastle, K., Perry, C., Langdon, R., \& Ziegler, J. (2001). DRC: A dual route cascaded model of visual word recognition and reading aloud. Psychological Review, 108, 204-256.

de Kovel, C. G., Hol, F. A., Heister, J. G., Willemen, J. J., Sandkuijl, L. A., Franke, B.,...Padberg, G. W. (2004). Genomewide scan identifies susceptibility locus for dyslexia on Xq27 in an extended Dutch family. Journal of Medical Genetics, 41 (9), 652-657. 
Dehaene, S., Pegado, F., Braga, L., Ventura, P., Nunes Filho, G., Jobert, A., ... Cohen, L. (2010). How learning to read changes the cortical networks for vision and language. Science 330, 1359-1364.

de Jong, P. F. (2011). What discrete and serial rapid automatized naming can reveal about reading. Scientific Studies of Reading, 15, 314-337.

Denckla, M. B., \& Rudel, R. G. (1976). Rapid 'automatized' naming (R.A.N.):

Dyslexia differentiated from other learning disabilities. Neuropsychologia, $14,471-479$.

Elliott, J. G., \& Grigorenko, E. L. (2014). The dyslexia debate. Cambridge University Press.

Facoetti, A., Trussardi, A. N., Ruffino, M., Lorusso, M. L., Cattaneo, C., Galli, R., ... \& Zorzi, M. (2010). Multisensory spatial attention deficits are predictive of phonological decoding skills in developmental dyslexia. Journal of Cognitive Neuroscience, 22, 1011-1025.

Facoetti, A., Zorzi, M., Cestnick, L., Lorusso, M. L., Molteni, M., Paganoni, P., ... \& Mascetti, G. G. (2006). The relationship between visuo-spatial attention and nonword reading in developmental dyslexia. Cognitive Neuropsychology, 23, 841-855.

Ford, D. H. \& Lerner, R. M. (1992). Developmental systems theory: An integrative approach. Newsbury Park, CA: Sage.

Franceschini, S., Gori, S., Ruffino, M., Pedrolli, K., \& Facoetti, A. (2012). A causal link between visual spatial attention and reading acquisition. Current Biology, 22, 814-819.

Gaab, N., Gabrieli, J. D. E., Deutsch, G. K., Tallal, P., \& Temple, E. (2007). Neural correlates of rapid auditory processing are disrupted in children with 
developmental dyslexia and ameliorated with training: An fMRI study. Restorative Neurology and Neuroscience, 25, 295-310.

Gabrieli, J. D. E. (2009). Dyslexia: A new synergy between education and cognitive neuroscience. Science, 325, 280-283.

Georgiou, G. K., Aro, M., Liao, C. H., \& Parrila, R. (2015). The contribution of RAN pause time and articulation time to reading across languages: Evidence from a more representative sample of children. Scientific Studies of Reading, 19, 135-144.

Georgiou, G. \& Parrila, R. (2012). Rapid naming and reading. In L. Swanson, K. Harris \& S. Graham (eds.), Handbook of Learning Disabilities (2 ${ }^{\text {nd }}$ ed., pp. 169185). New York: Guilford.

Georgiou, G. K., Parrila, R., Cui, Y., \& Papadopoulos, T. C. (2013). Why is rapid automatized naming related to reading? Journal of Experimental Child Psychology, 115, 218-225.

Giraud, A.-L. \& Ramus, F. (2013). Neurogenetics and auditory processing in developmental dyslexia. Current Opinion in Neurobiology, 23, 37-42.

Gordon, P. C., \& Hoedemaker, R. S. (in press). Effective scheduling of looking and talking during rapid automatized naming. Journal of Experimental Psychology: Human Perception and Performance. Advance online publication. http://dx.doi.org/10.1037/xhp0000171

Gori, S., \& Facoetti, A. (2015). How the visual aspects can be crucial in reading acquisition? The intriguing case of crowding and developmental dyslexia. Journal of Vision, 15 (1): 8, 1-20.

Goswami, U. (2011). A temporal sampling framework for developmental dyslexia. Trends in Cognitive Sciences, 15, 3-10. 
Goswami, U. (2015). Sensory theories of developmental dyslexia: three challenges for research. Nature Reviews Neuroscience, 16, 43-54.

Gottlieb, G. (1983). The psychobiological approach to developmental issues. In M. M. Haith \& J. J. Campos (Eds.), Handbook of child psychology (4th ed., vol. 2, pp. 1-26). New York: John Wiley \& Sons.

Gottlieb, G. (1991). Experiential canalization of behavioral development: Theory. Developmental Psychology, 27, 4-13.

Gottlieb, G. (1997). Synthesizing nature-nurture: Prenatal roots of instinctive behavior. Mahwah, NJ: Lawrence Erlbaum Associates.

Gottlieb, G. (2002). Individual development and evolution. Mahwah, NJ: Lawrence Erlbaum Associates.

Gottlieb, G. \& Halpern, C. T. (2002). A relational view of causality in normal and abnormal development. Development and Psychopathology, 14, 421-435.

Gottlieb, G., Wahlsten, D., \& Lickliter, R. (2006). The significance of biology for human development: A developmental psychobiological systems view. In R. M. Lerner \& W. Damon (Eds.), Handbook of child psychology (6 ed., Vol. 1, pp. 210-257). Hoboken, NJ: John Wiley \& Sons.

Griffiths, P. E. \& Tabery, J. (2013). Developmental systems theory: What does it explain, and how does it explain it? In R. M. Lerner \& J. B. Benson (eds.), Advances in child development and behavior (vol. 44, pp. 65-94). Waltham, MA: Academic Press.

Hallgren, B. (1950). Specific dyslexia (congenital word-blindness); a clinical and genetic study. Acta Psychiatrica et Neurologica Scandinavica Supplementum, 65, 1-287. 
Hazan, V., Messaoud-Galusi, S., Rosen, S., Nouwens, S., \& Shakespeare, B. (2009). Speech perception abilities of adults with dyslexia: is there any evidence for a true deficit? Journal of Speech, Language, and Hearing Research, 52, $1510-1529$.

International Dyslexia Association (2002). Definition of dyslexia. Retrieved May 15, 2015, from http://eida.org/definition-of-dyslexia/

Jablonka, E. \& Lamb, M. J. (2014). Evolution in four dimensions (rev. ed.). Cambridge, MA: The MIT Press.

Jednorog, K., Marchewka, A., Altarelli, I., Monzalvo Lopez, A. K., van ErmingenMarbach, M., Grande, M., Grabowska, A., Heim, S. \& Ramus, F. (2015). How reliable are gray matter disruptions in specific reading disability across multiple countries and Languages? Insights from a Large-scale voxelbased morphometry study. Human Brain Mapping, 36, 1741-1754.

Jones, M. W., Branigan, H. P., \& Kelly, M. L. (2009). Dyslexic and nondyslexic reading fluency: Rapid automatized naming and the importance of continuous lists. Psychonomic Bulletin \& Review, 16, 567-572.

Kere, J. (2014). The molecular genetics and neurobiology of developmental dyslexia as model of a complex phenotype. Biochemical and Biophysical Research Communications, 452, 236-243.

Kirby, J. R., Georgiou, G. K., Martinussen, R., \& Parrila, R. (2010). Naming speed and reading: From prediction to instruction. Reading Research Quarterly, $45,341-362$.

Kirby, J. R., Parrila, R. K. \& Pfeiffer, S. L. (2003). Naming speed and phonological awareness as predictors of reading development. Journal of Educational Psychology, 95, 453-464. 
Krafnick , A. J., Flowers, D. L., Luetje, M. M., Napoliello, E. M. \& Eden, G. F. (2014) An investigation into the origin of anatomical differences in dyslexia. The Journal of Neuroscience, 34, 901-908.

Linkersdörfer, J., Lonnemann, J., Lindberg, S., Hasselhorn, M., \& Fiebach, C. J. (2012). Grey matter alterations co-localize with functional abnormalities in developmental dyslexia: An ALE meta-analysis. PLoS ONE, 7 (8), e43122. doi:10.1371/journal.pone.0043122

Lobier, M. A., Peyrin, C., Pichat, C., Le Bas, J. F., \& Valdois, S. (2014). Visual processing of multiple elements in the dyslexic brain: Evidence for a superior parietal dysfunction. Frontiers in Human Neuroscience, 8, 479.

Lobier, M., Zoubrinetzky, R., \& Valdois, S. (2012). The visual attention span deficit in dyslexia is visual and not verbal. Cortex, 48, 768-773.

Lyytinen, H., Ahonen, T., Aro, M., Aro, T., Närhi, V., \& Räsänen, P. (1998). Learning disabilities: A view of developmental neuropsychology. In R. Licht, A. Bouma, W. Slot, \& W. Koops (Eds.), Child neuropsychology: Reading disability and more. Delft, NL: Eburon.

Magnuson, J. S., Kukona, A., Braze, D., Johns, C. L., Van Dyke, J. A., Tabor, W., Mencl, W. E., Pugh, K. R., \& Shankweiler, D. (2011). Phonological instability in young adult poor readers: Time course measures and computational modeling. In P. McCardle, B. Miller, J. R. Lee, \& O. J. L. Tseng (Eds.). Dyslexia across languages (pp. 184-201). Baltimore, MD: Paul H. Brookes.

Manis, F. R., Seidenberg, M. S., Doi, L. M., McBride-Chang, C., \& Petersen, A. (1996). On the bases of two subtypes of development dyslexia. Cognition, 58, 157-195. 
Manis, F. R., Seidenberg, M. S., Stallings, L., Joanisse, M., Bailey, C., Freedman, L., ... \& Keating, P. (1999). Development of dyslexic subgroups. Annals of Dyslexia, 49, 105-134.

Maisog, J. M., Einbinder, E. R., Flowers, D. L., Turkeltaub, P. E. \& Eden, G. F. (2008). A meta-analysis of functional neuroimaging studies of dyslexia. Annals of the New York Academy of Sciences, 1145, 237-259.

McCardle, P., Miller, B., Lee, J. R., \& Tzeng, O. J. L. (2011). Dyslexia across languages: Orthography and the brain-gene-behavior link. Baltimore, MD: Paul H. Brookes.

Molenaar, P. C. M., Lerner, R. M., \& Newell, K. M. (eds.)(2014). Handbook of developmental systems theory and methodology. New York: Guilford.

Nation, K., \& Snowling, M. (1998). Semantic processing and the development of word-recognition skills: Evidence from children with reading comprehension difficulties. Journal of Memory and Language, 39, 85-101.

Noordenbos, M. W., Segers, E., Serniclaes, W., \& Verhoeven, L. (2013). Neural evidence of the allophonic mode of speech perception in adults with dyslexia. Clinical Neurophysiology, 124, 1151-1162.

Nopola-Hemmi, J. , Taipale, M., Haltia, T., Lehesjoki, A-E., Voutilainen, A. \& Kere, J. (2000). Two translocations of chromosome $15 q$ associated with dyslexia. Journal of Medical Genetics, 37, 771-775.

Norton, E. S., \& Wolf, M. (2012). Rapid automatized naming (RAN) and reading fluency: Implications for understanding and treatment of reading disabilities. Annual Review of Psychology, 63, 427-452.

Nurmi, J. - E. (2012) Students' characteristics and teacher-child relationships in instruction: A meta-analysis. Educational Research Review, 7, 177-197. 
Parrila, R. K., Kirby, J. R., McQuarrie, L. (2004). Articulation rate, naming speed, verbal short-term memory, and phonological awareness: Longitudinal predictors of early reading development? Scientific Studies of Reading, 8, $3-26$.

Perfetti, C. A. (1992). The representation problem in reading acquisition. In P. B. Gough, L. C. Ehri, \& R. Treiman (Eds.), Reading acquisition (pp. 145-174). Hillsdale, NJ: Lawrence Erlbaum.

Pennington, B. F. (2006). From single to multiple deficit models of developmental disorders. Cognition, 101, 385-413.

Pennington, B. F., Santerre-Lemon, L., Rosenberg, J., McDonald, B., Boada, R., Friend, A. ... Olson, R. K. (2012). Individual prediction of dyslexia by single versus multiple deficit models. Journal of Abnormal Psychology, 121, 212224.

Plaut, D. C., McClelland, J. L., Seidenberg, M. S., \& Patterson, K. (1996). Understanding normal and impaired word reading: Computational principles in quasi-regular domains. Psychological Review, 103, 56-115.

Protopapas, A. (2014) From temporal processing to developmental language disorders: mind the gap. Philosophical Transactions of the Royal Society B: Biological Sciences, 369 (1634), 1-11.

Protopapas, A., Altani, A., \& Georgiou, G. K. (2013). Development of serial processing in reading and rapid naming. Journal of Experimental Child Psychology, 116, 914-929.

Pugh, K. R., Mencl, W. E., Jenner, A. R., Katz, L., Frost, S. J., Lee, J. R., et al. (2000). Functional neuroimaging studies of reading and reading disability (developmental dyslexia). Mental Retardation \& Developmental 
Disabilities Research Reviews, 6, 207-213.

Rack, J. P., Snowling, M. J., \& Olson, R. K. (1992). The nonword reading deficit in developmental dyslexia: A review. Reading Research Quarterly, 27, 29-53.

Railsback, S. F. \& Grimm, V. (2011). Agent-based and individual-based modeling: A practical introduction. Princeton, NJ: Princeton University Press.

Ramus, F. (2003). Developmental dyslexia: specific phonological deficit or general sensorimotor dysfunction? Current Opinion in Neurobiology, 13, $212-218$.

Ramus, F., \& Ahissar, M. (2012). Developmental dyslexia: The difficulties of interpreting poor performance, and the importance of normal performance. Cognitive Neuropsychology, 29, 104-122.

Ramus, F., Rosen, S., Dakin, S. C., Day, B. L., Castellote, J. M., White, S., \& Frith, U. (2003). Theories of developmental dyslexia: insights from a multiple case study of dyslexic adults. Brain, 126, 841-865.

Ramus, F., \& Szenkovits, G. (2008). What phonological deficit? The Quarterly Journal of Experimental Psychology, 61, 129-141.

Ramus, F., \& Szenkovits, G. (2009). Understanding the nature of the phonological deficit. In K. Pugh \& P. McCardle (Eds.), How children learn to read (pp. 153-169). New York, NY: Psychology Press.

Richlan, F., Kronbichler, M., \& Wimmer, H. (2009). Functional abnormalities in the dyslexic brain: A quantitative meta-analysis of neuroimaging studies. Human Brain Mapping, 30, 3299-3308.

Richlan, F., Kronbichler, M., \& Wimmer, H. (2011). Meta-analyzing brain dysfunctions in dyslexic children and adults. Neuroimage, 56, 1735-1742.

Richlan, F., Kronbichler, M., \& Wimmer, H. (2013). Structural abnormalities in the 
dyslexic brain: A meta-analysis of voxel-based morphometry studies. Human Brain Mapping, 34, 3055-3065.

Ricketts, J., Nation, K., \& Bishop, D.V.M. (2007). Vocabulary is important for some, but not all reading skills. Scientific Studies of Reading, 11, 235-257.

Rosen, S., \& Manganari, E. (2001). Is there a relationship between speech and nonspeech auditory processing in children with dyslexia? Journal of Speech, Language, and Hearing Research, 44, 720-736.

Ruffino, M., Gori, S., Boccardi, D., Molteni, M., \& Facoetti, A. (2014). Spatial and temporal attention in developmental dyslexia. Frontiers in Human Neuroscience, 8, 331.

Serniclaes, W., Van Heghe, S., Mousty, P., Carré, R., \& Sprenger-Charolles, L. (2004). Allophonic mode of speech perception in dyslexia. Journal of Experimental Child Psychology, 87, 336-361.

Share, D. L. (2008). On the anglocentricities of current reading research and practice: The perils of overreliance on an "outlier" orthography. Psychological Bulletin, 134, 584-615.

Shaywitz, S. E. (1996). Dyslexia. Scientific American, 275 (5), 98-104.

Simos, P. G., Fletcher, J. M., Bergman, E., Breier, J. I., Foorman, B. R., Castillo, E.M., Davis, R.N., Fitzgerald, M., \& Papanicolaou, A. C. (2002). Dyslexia-specific brain activation profile becomes normal following successful remedial training. Neurology, 58, 1203-1213.

Snowling, M. J. (2000). Dyslexia (2nd ed.). Oxford, UK: Blackwell.

Snowling, M. J. (2013). Early identification and interventions for dyslexia: A contemporary view. Journal of Research in Special Educational Needs, 13 (1), 7-14. 
Snowling, M. J. \& Melby-Lervåg, M. (2016, January 4). Oral language deficits in familial dyslexia: A meta-analysis and review. Psychological Bulletin. Advance online publication. http://dx.doi.org/10.1037/bul0000037.

Stanovich, K. E., Siegel, L. S., \& Gottardo, A. (1997). Converging evidence for phonological and surface subtypes of reading disability. Journal of Educational Psychology, 89, 114-127.

Steacy, L. M., Kirby, J. R., Parrila, R., \& Compton, D. L. (2014). Classification of double deficit groups across time: An analysis of group stability from kindergarten to second grade. Scientific Studies of Reading, 18, 255-273.

Tabery, J. (2014). Beyond versus: The struggle to understand the interaction between nature and nurture. Cambridge, MA: The MIT Press.

Tallal, P. (1980). Auditory temporal perception, phonics, and reading disabilities in children. Brain and Language, 9, 182-198.

Thelen, E. \& Smith, L. B. (1994). A dynamic systems approach to the development of cognition and action. Cambridge, MA: The MIT Press.

Torppa, M., Eklund, K., van Bergen, E., \& Lyytinen, H. (2015). Late-emerging and resolving dyslexia: A follow-up study from age 3 to 14. Journal of Abnormal Child Psychology, 43, 1389-1401.

Torppa, M., Parrila, R., Niemi, P., Poikkeus, A.-M., Lerkkanen, M.-K., \& Nurmi, J.-E. (2013). The double deficit hypothesis in the transparent Finnish orthography: a longitudinal study from kindergarten to grade 2. Reading and Writing: An Interdisciplinary Journal, 26, 1353-1380.

Tunmer, W. \& Greaney, K. (2010). Defining dyslexia. Journal of Learning Disabilities, 43, 229-243.

van Bergen, E., Bishop, D. V. M., van Zuijen, T. L., \& de Jong, P. F. (2015). How does 
parental reading influence children's reading. A study of cognitive mediation. Scientific Studies of Reading, 19, 325-339.

van Bergen, E., van der Leij, A. \& de Jong, P. F. (2014). The intergenerational multiple deficit model and the case of dyslexia. Frontiers in Human Neuroscience, $8,346$.

van den Boer, M., Georgiou, G. K., \& de Jong, P. F. (2016). Naming of short words is (almost) the same as naming of alphanumeric symbols: Evidence from two orthographies. Journal of Experimental Child Psychology, 144, 152165.

Van den Broeck, W., \& Geudens, A. (2012). Old and new ways to study characteristics of reading disability: The case of the nonword-reading deficit. Cognitive Psychology, 65, 414-456.

Vandermosten, M., Boets, B., Wouters, J. \& Ghesquière, P. (2012). A qualitative and quantitative review of diffucsion tensor imaging studies in reading and dyslexia. Neuroscience and Biobehavioral Reviews, 36, 1532-1552

Velicer, W. F., Babbin, S. F., \& Palumbo, R. (2014). Idiographic applications: Issues of ergodicity and generalizability. In P. C. M. Molenaar, R. M.,Lerner \& K. M. Newell (eds.), Handbook of developmental systems theory and methodology (pp. 425-441). New York: Guilford.

Vellutino, F. R., Scanlon, D. M., Sipay, E. R., Small, S. G., Pratt, A., Chen, R. S., \& Denckla, M. S. (1996). Cognitive profiles of difficult-to-remediate and readily remediated poor readers: Early intervention as a vehicle for distinguishing between cognitive and experiential deficits as basic causes of specific reading disability. Journal of Educational Psychology, 88, 601638. 
Vellutino, F. R., Fletcher, J. M., Snowling, M. J., \& Scanlon, D. M. (2004). Specific reading disability (dyslexia): What have we learned in the past four decades? Journal of Child Psychology and Psychiatry, 45, 2-40.

Vidyasagar, T. R., \& Pammer, K. (2010). Dyslexia: a deficit in visuo-spatial attention, not in phonological processing. Trends in Cognitive Sciences, 14, $57-63$.

Waters, C. K. (2007). Causes that make a difference. Journal of Philosophy, 104, $551-579$

Wilensky, U. \& Rand, W. (2015). An introduction to agent-based modeling: Modeling natural, social and engineered complex systems with NetLogo. Cambridge, MA: The MIT Press.

Wolf, M., \& Bowers, P. G. (1999). The double-deficit hypothesis for the developmental dyslexias. Journal of Educational Psychology, 91, 415-438.

Wolf, M., Bowers, P. G., \& Biddle, K. (2000). Naming-speed processes, timing, and reading: A conceptual review. Journal of Learning Disabilities, 33, 387407.

Woollams, A. M. (2014). Connectionist neuropsychology: Uncovering ultimate causes of acquired dyslexia. Philosophical Transactions of the Royal Society B: Biological Sciences, 369, 20120398.

Ziegler, J. C., \& Goswami, U. (2005). Reading acquisition, developmental dyslexia, and skilled reading across languages: A psycholinguistic grain size theory. Psychological Bulletin, 131, 3-29.

Ziegler, J. C., Pech-Georgel, C., Dufau, S., \& Grainger, J. (2010). Rapid processing of letters, digits and symbols: what purely visual-attentional deficit in developmental dyslexia? Developmental Science, 13, F8-F14. 
Zoccolotti, P., De Luca, M., Lami, L., Pizzoli, C., Pontillo, M., \& Spinelli, D. (2013). Multiple stimulus presentation yields larger deficits in children with developmental dyslexia: A study with reading and RAN-type tasks. Child Neuropsychology, 19, 639-647.

Zoccolotti, P., De Luca, M., \& Spinelli, D. (2015). Discrete versus multiple word displays: A re-analysis of studies comparing dyslexic and typically developing children. Frontiers in Psychology, 6, 01530.

Zoubrinetzky, R., Bielle, F., \& Valdois, S. (2014). New insights on developmental dyslexia subtypes: Heterogeneity of mixed reading profiles. PloS one, 9, e99337. 
Level of Analysis

Etiologic Risk and

Protective Factors

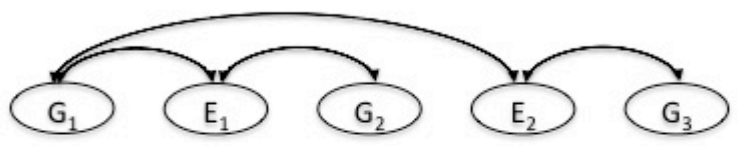

Neural Systems

Cognitive Processes

Complex Behavioral Disorders
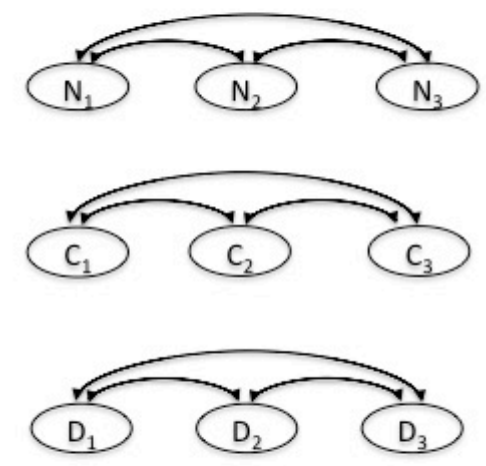

Non-independence

at each level

GxE interaction \&

G-E correlation

Pleiotropy

Interactive

development

Comorbidity

KEY: $\mathrm{G}=$ genetic risk or protective factor; $\mathrm{E}=$ environmental risk or protective factor; $N=$ neural system; $C=$ cognitive process; $D=$ disorder

Figure 1. Pennington's (2006) Probabilistic Multiple Deficit Model. Note that causal connections (and feedback loops) between levels not shown in the figure but acknowledged in the text. 


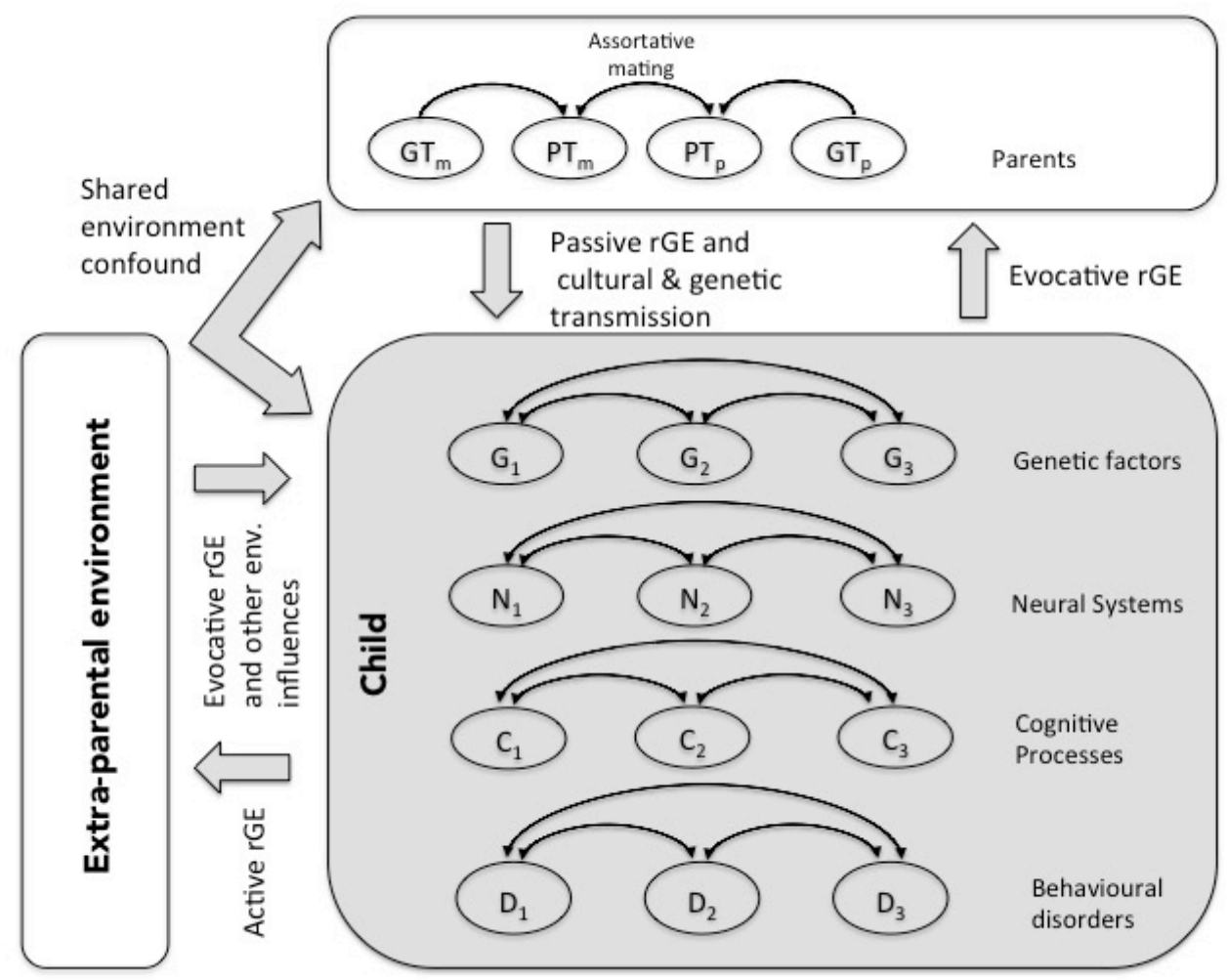

Figure 2. van Bergen, van der Leij and de Jong's (2014) intergenerational multiple deficit model (see van Bergen et al., 2014, for detailed descriptions of components). 